\title{
Effect Analysis on the Performance Enhancement and Emission Reduction of Diesel Engine Fueled with Biodiesel Fuel Based on an Improved Model
}

\author{
Weigang Yu $\mathbb{D}^{1}$, Zhiqing Zhang $\mathbb{D}^{2}{ }^{2}$ and Bo Liu $\mathbb{D}^{3}$ \\ ${ }^{1}$ Hunan Valin Xiangtan Iron \& Steel Co., Ltd, Xiangtan 411101, China \\ ${ }^{2}$ School of Mechanical and Transportation Engineering, Guangxi University of Science and Technology, Liuzhou 545006, China \\ ${ }^{3}$ School of Electrical Engineering, Hunan Institute of Engineering, Xiangtan 411104, China
}

Correspondence should be addressed to Zhiqing Zhang; zhangzhiqing@gxust.edu.cn

Received 6 September 2020; Revised 25 October 2020; Accepted 26 November 2020; Published 11 December 2020

Academic Editor: Gang Wu

Copyright ( $) 2020$ Weigang Yu et al. This is an open access article distributed under the Creative Commons Attribution License, which permits unrestricted use, distribution, and reproduction in any medium, provided the original work is properly cited.

\begin{abstract}
To increase the efficiency and accuracy of computing, an improved combined weight coefficient is used to develop an improved heat transfer model in AVL-BOOST environment. Similarly, a five-component biodiesel skeletal mechanism is employed to investigate the combustion process of biodiesel fuel. Then, the AVL-BOOST model is validated by the experimental results under different conditions. Finally, the improved heat transfer model is employed to investigate the propulsion and load characteristics of diesel engine fueled with biodiesel fuel in terms of power, BSFC, soot, and $\mathrm{NO}_{\mathrm{x}}$ emission. The result shows that the errors between experiment and simulation are less than $2 \%$ and the simulation model can predict the propulsion and load characteristics of the diesel engine. In addition, the comprehensive characteristic of case 5 is the best. Moreover, the big inject orifice is not beneficial to the fuel atomization and more soot is produced. Thus, it is very important to choose the appropriate injection rate reasonably.
\end{abstract}

\section{Introduction}

Due to the reliability and economy of diesel engine, the diesel engine has become the main power source of mechanical equipment [1], such as the ship, construction machinery [2], and heavy-duty truck [3]. The diesel engines have become the main power source for ships, construction machinery, heavy trucks, and other mechanical equipment, because of the reliability and economy of diesel engine. Particulate matter $(\mathrm{PM})$ and $\mathrm{NO}_{\mathrm{x}}$ emissions from diesel engines pose a threat to the ecosystem and public health [4]. With the successive implementation of the "supplementary provisions" [5], the higher requirements have been put forward on how to reduce $\mathrm{NO}_{\mathrm{x}}$ and $\mathrm{PM}$ emissions and improve the performance of diesel engine [6]. To meet the requirements of the regulations, renewable energy sources should be developed to replace fossil fuels [7] and the system structure of existing diesel engines should be improved to adapt the needs of new fuels $[8,9]$.
As a new type of renewable energy, biodiesel fuel is a good alternative of petrochemical energy and has been highly concerned and expected by experts and scholars in recent years [10]. Biodiesel is not only a new type of renewable energy but also a good substitute of petrochemical energy, so it has attracted great attention and expectation in recent years. Compared with fossil fuels, biodiesel is nontoxic and biodegradable, and its emission is significantly reduced $[11,12]$. Furthermore, unfortunately, some factors will result in quality degradation, such as light, metal contamination, and oxygen exposure, but these reductions can be mitigated by some technologies and additives [13]. Thus, lots of researchers had carried out the research on biodiesel fuel [14]. This is exactly what many researchers explore and research on biodiesel. Zhang et al. found that the high oxygen content of biodiesel improved combustion and greatly reduced $\mathrm{HC}$ and $\mathrm{CO}$ emissions [15]. The work carried out by Liu et al. showed that the addition of biodiesel caused the increase of BSFC and the reduction in torque. It is due 
to the shorter ignition delay and lower calorific of biodiesel [16]. In addition, the similar phenomena were found by Can [17] and Özener et al. [18]. Imdadul et al. had found that proper pentanol in biodiesel could reduce BSFC and improve the performance of biodiesel [19]. Further, the emission studies showed that the addition of biodiesel did significantly reduce $\mathrm{CO}$ and $\mathrm{HC}$ emissions [20], but $\mathrm{NO}_{\mathrm{x}}$ emissions increased significantly $[21,22]$. Because the spray performance has a great impact on the combustion and emission characteristics of biodiesel, it is necessary to study the spray performance and improve the applicability and development of biodiesel [23].

Diesel engine combustion is a complex and changeable physical and chemical process [24]. Under the condition of limited resources in China, researchers often apply a numerical method to solve the scheme selection and design improvement, so as to improve the efficiency and reduce the design cost of diesel engine [25]. The designer only chooses the corresponding model and inputs the diesel engine parameters [26], then can make a preliminary demonstration of the model, because the modeling and simulation software provides a predesign platform [27]. For instance, Lino et al. had established a nonlinear injection system model for a common rail diesel engine [28]. They found that the model verified by experiment could predict accurately the spray process and the good spray performance improves the combustion process of diesel engine. The simulation model of an electronic control unit (ECU) pump injection system was established by Lähde et al., and the influence of various structural parameters on its economy and emission characteristics was studied [29]. The result showed that different fuel injection mass had a great impact on emission and performance characteristics of diesel engine. In addition, $\mathrm{Wu}$ et al. had developed a numerical model of diesel particulate filter and investigated on the effects of key factors on the performance of $\mathrm{CeO}_{2}$-based catalyzed diesel particulate filter. They found that the soot regeneration rate and the $\mathrm{N}_{2} \mathrm{O}$ concentration first increased and then decreased as the exhaust gas temperature increased and the higher exhaust gas temperature suppressed the production of $\mathrm{N}_{2} \mathrm{O}$ but raised the possibility of catalyst poisoning [30]. The research conclusions showed that the delay of the solenoid valve was an important factor. Frosina et al. had proposed a one-dimensional fuel injection system (FIS) model to explore the impact of biodiesel on the performance characteristic of common rail diesel engines [31]. The simulation results were consistent with the experimental results. There are many literatures about diesel engine emission and performance characteristics, which mainly focus on the fuel injection system model of diesel engine, but there are few researches on the mechanical injection system modification of electronic control injection system [32]. Therefore, the software provides a good idea for modeling diesel engine fuel injection system, and it can effectively analyze the fuel injection rate of diesel engine [33].

Typically, the researchers often used GT Power and ALV-BOOST software to investigate the effect of zerodimensional or dual-zone combustion model on diesel engine performance [34] and emission characteristics and input different parameters to study its impact on overall parameters of diesel engine $[35,36]$. For example, Ma et al. established a simulation model by using AVL-BOOST and neural network software to study the relative contribution of operating parameters on the emission and performance characteristics of common rail diesel engine in terms of torque, smoke, $\mathrm{NO}_{\mathrm{x}}$, and braking specific fuel consumption (BSFC) [37]. Similarly, some scholars used the AVLBOOST software [38] to establish the simulation model of the diesel engine and analyzed the influence of different fuel ratios on the comprehensive performance of the diesel engine $[39,40]$. In addition, other scholars had carried out the modeling and made the analysis of four main factors which could impact the performance and emission characteristics of diesel engine, including the first and the second injection mass ratio [40], interval time [41], main injection start time [42], and exhaust gas recirculation (EGR) ratio [43]. However, the one-dimensional models are simpler, faster and included more detailed physical models [44]. Therefore, more advanced models should be adopted, including simulations of combustion, heat transfer and pollutant formation processes [45].

In this paper, an improved heat transfer model is established by using the combined weight coefficients to simulate the combustion and heat transfer process of diesel engine fueled with biodiesel in AVL-BOOST environment. In addition, the five-component biodiesel skeletal mechanism is used to predict the combustion process of biodiesel. The AVL-BOOST model is validated by the experimental results under different conditions. Moreover, the new model is employed to analyze the engine characteristic and investigate the effect of fuel injection rate on the engine characteristic of diesel engine fueled with biodiesel fuel.

\section{Materials and Methods}

\subsection{Mathematical Model}

2.1.1. AVL MCC Combustion Model. To improve the calculation accuracy, the paper uses the quasidimensional MCCAVL combustion model to predict the combustion in the cylinder. The model considers the influence of diffusion combustion and premixing, and it can predict the emission characteristic of diesel engine accurately. The expression of heat release rate is expressed as follows:

$$
\frac{d Q_{\mathrm{F}}}{d \varphi}=\frac{d Q_{\mathrm{MCC}}}{\mathrm{d} \varphi}+\frac{d Q_{\mathrm{PMC}}}{d \varphi},
$$

where $Q_{F}$ is the combustion heat release rate, $Q_{M C C}$ is the total heat release rate of diffusion combustion, $Q_{\mathrm{PMC}}$ is the total heat release rate of premixed combustion, and $\varphi$ is the crank angle.

The total heat release rate of diffusion combustion is expressed as

$$
\frac{d Q_{\mathrm{MCC}}}{d \varphi}=C_{\mathrm{comb}} \cdot\left(m_{\mathrm{F}}-\frac{Q_{\mathrm{MCC}}}{H_{\mathrm{u}}}\right) \cdot\left(w_{\mathrm{Air}}\right)^{C_{\mathrm{EGR}}} \cdot C_{\mathrm{Rate}} \cdot \frac{\sqrt{k}}{\sqrt[3]{V}}
$$


where $Q_{\mathrm{MCC}}$ is the total heat release rate of diffusion combustion, $C_{\text {comb }}$ is the combustion constant, $m_{\mathrm{F}}$ is the evaporative fuel mass, $H_{\mathrm{u}}$ is the low calorific value of fuel oil, $k$ is the turbulent energy density, $w_{\text {Air }}$ is the effective air mass fraction, $C_{\mathrm{EGR}}$ is the EGR influence constant, and $C_{\text {Rate }}$ is the mixing ratio constant.

The actual heat release rate of premixed combustion is expressed as

$$
\begin{aligned}
\frac{1}{Q_{\mathrm{PMC}}} \frac{d Q_{\mathrm{PMC}}}{d \varphi} & =\frac{6.908}{\Delta \varphi_{\mathrm{C}}} \cdot(m+1) \cdot\left(\frac{\varphi-\varphi_{\mathrm{B}}}{\Delta \varphi_{\mathrm{C}}}\right) \\
& \cdot \exp \left[-6.908 \cdot\left(\frac{\varphi-\varphi_{\mathrm{B}}}{\Delta \varphi_{\mathrm{C}}}\right)^{(m+1)}\right],
\end{aligned}
$$

where $Q_{\mathrm{PMC}}$ is the total heat release rate of premixed combustion, $\varphi$ is the crank angle, $\Delta \varphi_{\mathrm{C}}$ is the premixed combustion duration, $\varphi_{\mathrm{B}}$ is the start of combustion angle, and $m$ is the shape parameter.

2.1.2. Heat Transfer Model. Heat transfer in a diesel engine cylinder is a very complex process. Woschni 1978 heat transfer model is generally used for calculation of high-pressure circulating heat transfer [32]. In the process of heat transfer, the influence of convective heat transfer in the cylinder is mainly considered [33]. The Woschni model published in 1978 for the high-pressure cycle is summarized as follows:

$$
\alpha_{\mathrm{w}}=130 T_{\mathrm{c}}^{-0.2} p_{\mathrm{c}}^{0.8} D^{-0.2}\left[C_{1} C_{\mathrm{m}}+C_{2} \frac{V T_{\mathrm{IVC}}}{p_{\mathrm{IVC}} V_{\mathrm{IVC}}}\left(p_{\mathrm{c}}-p_{\mathrm{c}, \mathrm{o}}\right)\right]^{0.8}
$$

where $T_{c}$ is the cylinder temperature, $p_{c}$ is the cylinder pressure, $D$ is the cylinder diameter, $C_{1}$ is the gas velocity coefficient, $C_{\mathrm{m}}$ is the mean velocity of piston, $C_{2}$ is the model constant, $T_{\text {IVC }}$ is the inlet valve closing cylinder volume, $V$ is the actual cylinder volume, $p_{\text {IVC }}$ is the inlet valve closing cylinder pressure, and $p_{c, 0}$ is the inverted cylinder pressure.

The heat transfer coefficient of the Hohenberg heat transfer model is summarized as follows:

$$
\alpha_{\mathrm{k}}=130 \cdot V^{-0.06} \cdot p_{\mathrm{c}}^{0.8} \cdot T_{\mathrm{c}}^{-0.4} \cdot\left(c_{\mathrm{m}}+1.4\right)^{0.8},
$$

where $p_{c}$ is the cylinder pressure, $C_{m}$ is the mean velocity of piston, and $V$ is the actual cylinder volume.

One of the defects of the single heat transfer model is that the heat transfer in the diesel cylinder cannot be predicted accurately. In order to improve the calculation accuracy and make up for the shortage of a single model and based on the theory of optimized weighted array prediction, an optimized weighted array model of heat transfer in the diesel engine cylinder is established in this paper. The optimal weighting coefficients are derived by the minimum variance method. Thus, the advantages of the two models are combined. The combined model makes the model more accurate. The author uses the minimum variance method to find the optimal weighting coefficient in this paper. Therefore, the
TABLE 1: Main parameters of FIS of the ECU pump.

\begin{tabular}{lcc}
\hline Title & Parameter & Valve \\
\hline Plunger & Plunger diameter $(\mathrm{mm})$ & 13 \\
& Cam profile velocity $(\mathrm{mm} / \mathrm{CaA})$ & 0.46 \\
\hline Opening pressure $(\mathrm{MPa})$ & 19 \\
Injector & Maximum needle lift $(\mathrm{mm})$ & 0.4 \\
& Flow (ml/(30 sec $* 100 \mathrm{bar}))$ & 1500 \\
& Orifice number & 8 \\
High-pressure oil & Orifice diameter $(\mathrm{mm})$ & 0.26 \\
\hline pipe & Length (mm) & 900 \\
& Internal diameter $(\mathrm{mm})$ & 2 \\
\hline Solenoid valve & Rod diameter $(\mathrm{mm})$ & 6.98 \\
& Maximum rod lift $(\mathrm{mm})$ & 0.21 \\
& Solenoid valve residue air gap & 0.12 \\
& (mm) & 14.5 \\
\hline
\end{tabular}

advantages of these two modes are combined. The combined model makes the model more accurate.

Assume that $\alpha_{i}$ is the expected predictive value, and the experimental observation value is $X_{i}\left(X_{1}, X_{2}, \cdots, X_{n}\right)$. The predicted value of the Woschni 1978 heat transfer model is $\alpha_{\mathrm{w} i}(i=1,2, \cdots, n)$; the error between the model value and the test value is $e_{\mathrm{w} i}(i=1,2, \cdots, n)$. The predicted value of the second model is $\alpha_{\mathrm{k} i}(i=1,2, \cdots, n)$; the error between the second model value and test value is $e_{\mathrm{k} i}(i=1,2, \cdots, n)$. Respectively, the expected predictive value of $\alpha_{i}$ and error $e_{i}$ $(i=1,2, \cdots, n)$ are as follows:

$$
\alpha_{i}=w_{1} \alpha_{\mathrm{w} i}+w_{2} \alpha_{\mathrm{k} i}
$$

where $w_{1}$ is the weight coefficient of the Woschni 1978 heat transfer model and $w_{2}$ is the weight coefficient of the Hohenberg heat transfer model.

$$
e_{i}=w_{1} e_{\mathrm{w} i}+w_{2} e_{\mathrm{k} i}
$$

where $e_{1 i}, e_{2 i}, w_{1}$, and $w_{2}$ are defined as $w_{1}+w_{2}=1, e_{1 i}=$ $X_{i}-\alpha_{\mathrm{w} i}$, and $e_{2 i}=X_{i}-\alpha_{\mathrm{k} i}$.

The minimum quadratic sum of the combined expected forecasting error is as follows:

$\min \left(\sum e_{i}^{2}\right)=\min \left[w_{1}^{2} \sum e_{\mathrm{w} i}^{2}+2 w_{1} w_{2} \sum\left(e_{\mathrm{w} i} e_{\mathrm{k} i}\right)+w_{2}^{2} \sum e_{\mathrm{k} i}^{2}\right]$

with $w_{1}=\left[\sum e_{\mathrm{k} i}^{2}-\sum\left(e_{\mathrm{w} i} e_{\mathrm{k} i}\right)\right] /\left[\sum e_{\mathrm{w} i}^{2}+\sum e_{\mathrm{k} i}^{2}-2 \sum\left(e_{\mathrm{w} i} e_{\mathrm{k} i}\right)\right] \quad$ and $w_{2}=\left[\sum e_{\mathrm{w} i}^{2}-\sum\left(e_{\mathrm{w} i} e_{\mathrm{k} i}\right)\right] /\left[\sum e_{\mathrm{w} i}^{2}+\sum e_{\mathrm{k} i}^{2}-2 \sum\left(e_{\mathrm{w} i} e_{\mathrm{k} i}\right)\right]$.

It can be proved that $\min \left(\sum e_{i}^{2}\right) \leq \min \left(\sum e_{\mathrm{k} i}^{2}\right)$ and $\min \left(\sum e_{i}^{2}\right) \leq \min \left(\sum e_{\mathrm{w} i}^{2}\right)$. It shows that the combined heat transfer model is better than the single model prediction.

2.2. Fuel Injection System. The instantaneous injection rate (IFR) and the fuel injection pressure can be obtained by the oil pump testing device (6PSDW300). The IFR system is 


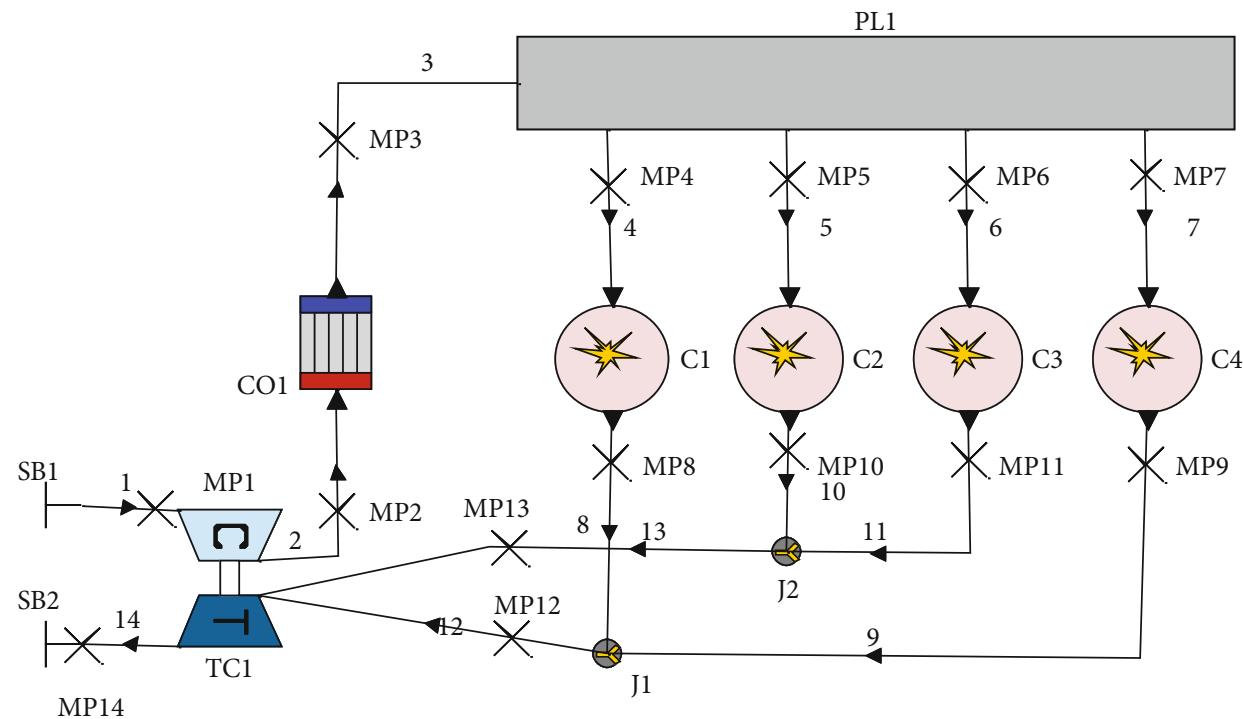

Figure 1: Simulation model of the entire diesel engine.

TABLE 2: Main parameters of diesel engine.

\begin{tabular}{lcc}
\hline Parameter & Unit & Value \\
\hline Cylinder diameter & $\mathrm{mm}$ & 190 \\
Number of cylinders & - & 4 \\
Rate speed & $\mathrm{r} / \mathrm{min}$ & 1000 \\
Peak pressure & $\mathrm{MPa}$ & 12 \\
Rated power & $\mathrm{kW}$ & 220 \\
Mean effective pressure & $\mathrm{MPa}$ & 1.109 \\
Compression ratio & - & 14 \\
\hline
\end{tabular}

composed of the electric control part and mechanical part. Moreover, the IFR was measured by the EFS8427 measurement units of French EFS Company. The main experiment steps can be expressed as follows:

Step 1. Preparation work. Check the oil pump testing device, fill the low-pressure oil tank with fuel, and install the electronic unit pump in the mechanical part. The electric control part is supplied by a single-phase current and connected to the computer through the Ethernet by a specific software as a user interface.

Step 2. Set the relevant operating parameters of the oil pump test bed. Start motor drive oil pump operation and transport oil from the low-pressure oil tank to the high-pressure common rail pipe. Fuel which is injected from the fuel injector will be collected in a constant static pressure fuel collection chamber.

The main parameters of FIS of the ECU pump is shown in Table 1. In the experimental process, the injection pressure and fuel supply pressure were measured by the pressure sensor installed in the mechanical part, and the original parameters such as the fuel injection rate and fuel injection mass were provided to the FIR control system.
TABle 3: Physical properties of fuel.

\begin{tabular}{lc}
\hline Item & Rapeseed oil methyl ester \\
\hline Oxygen content $(\% \mathrm{~m} / \mathrm{m})$ & 10.7 \\
Viscosity at $40^{\circ} \mathrm{C}\left(\mathrm{mm} \cdot \mathrm{s}^{-2}\right)$ & 4.56 \\
Cetane number $(-)$ & 53.88 \\
Lower calorific value $(\mathrm{MJ} / \mathrm{kg})$ & 39.53 \\
Density at $15^{\circ} \mathrm{C}\left(\mathrm{kg} \cdot \mathrm{m}^{-3}\right)$ & 882 \\
Saturation $(\%)$ & 4.45 \\
Methyl linoleate & 22.27 \\
Methyl linolenate & 8.11 \\
Methyl stearate & 0.87 \\
Methyl palmitate & 3.57
\end{tabular}

TABLE 4: List of measurements, the measuring range, and accuracy.

\begin{tabular}{lcc}
\hline Measurements & Measuring range & Accuracy \\
\hline Engine speed & $1-2000 \mathrm{rpm}$ & $\pm 0.2 \%$ \\
Exhaust gas temperature & $0-1000^{\circ} \mathrm{C}$ & $\pm 1^{\circ} \mathrm{C}$ \\
Torque & $0-5000 \mathrm{~N} \cdot \mathrm{m}$ & $\pm 0.2 \% \mathrm{FS}$ \\
$\mathrm{NO}_{\mathrm{x}}$ emissions & $0-5000 \mathrm{ppm}$ & Below $1.0 \% \mathrm{FS}$ \\
$\mathrm{CO}_{2}$ emission & $0-16 \% \mathrm{vol}$ & Below $\pm 1.0 \% \mathrm{FS}$ \\
$\mathrm{HC}$ emission & $0-20000 \mathrm{ppm}$ & Below $\pm 1.0 \% \mathrm{FS}$ \\
$\mathrm{CO}$ emission & $0-3000 \mathrm{ppm}$ & Below $\pm 1.0 \% \mathrm{FS}$ \\
Fuel consumption & $1000 \mathrm{~g}$ & $\pm 0.2 \%$ \\
Crank angle encoder & $0-720^{\circ} \mathrm{CA}$ & $\pm 0.2^{\circ} \mathrm{CA}$ \\
\hline
\end{tabular}

2.3. Simulation Model of Entire Diesel Engine. In order to investigate the steady-state and transient-state performance characteristic of diesel engine, the entire model of diesel engine was developed in the AVL-BOOST environment. Figure 1 shows the layout of the entire diesel engine. In addition, the main parameters of diesel engine are shown in Table 2 . The air cooled by the air cooler enters the cylinder 


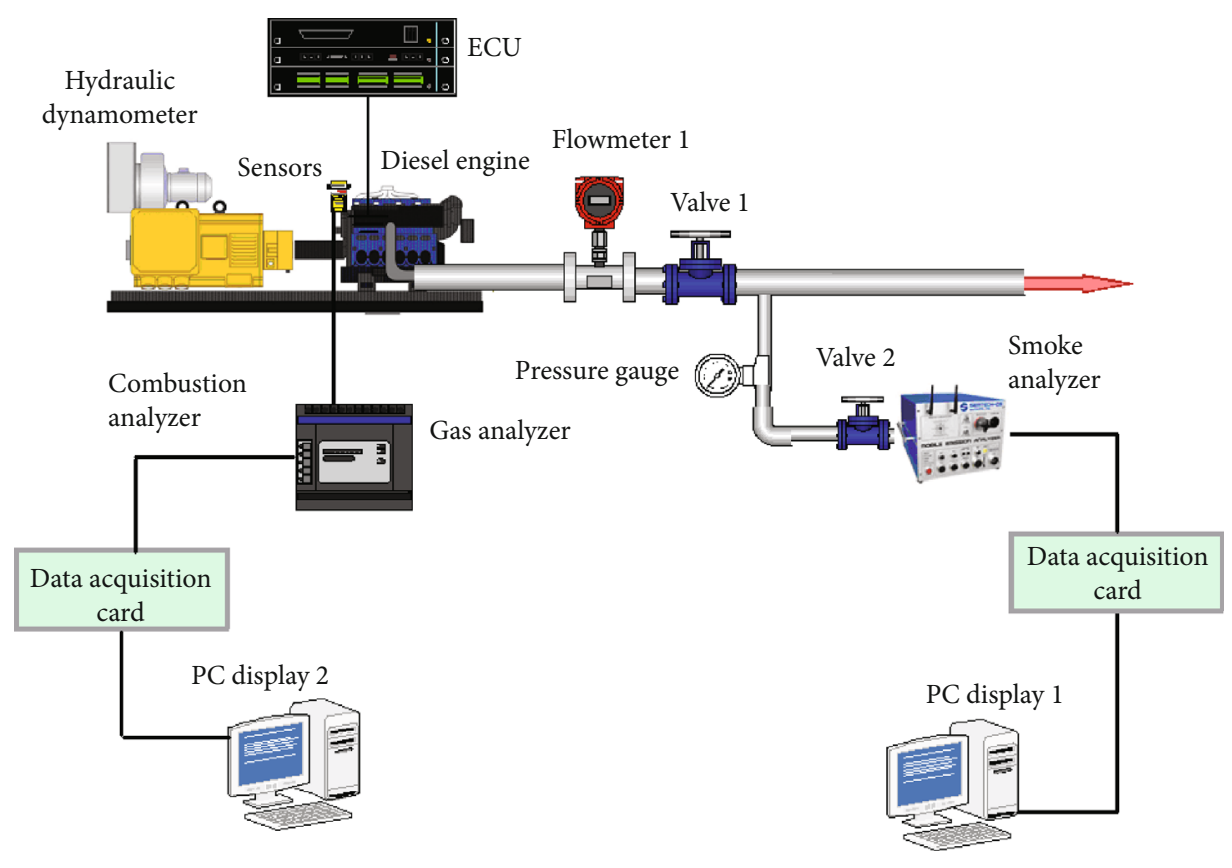

FIgURE 2: Schematics of experimental device.

through the air intake passage. After combustion process, the exhaust gases are discharged and flow into the turbine inlet. The turbine drives the turbocompressor, which delivers the compressed air to the cooler.

2.4. Fuel Sample Preparation. Rapeseed is widely grown in southern China, where nearly half the population uses the rapeseed oil as cooking oil. Therefore, the diesel engine fueled with the rapeseed methyl ester (RME) was studied experimentally. The RME can be obtained by the transesterification method, and the biodiesel can be widely used in diesel engines [16]. In addition, in the experimental reactor, the biodiesel transesterification was carried out by alkali catalysis about $1.2 \mathrm{~h}$. Actually, the transesterification conducted $1: 6$ oil molar to methanol ratio with $1 \% \mathrm{wt} / \mathrm{wt}$ potassium hydroxide as the alkaline catalyst. The physical properties of biodiesel are shown in Table 3. In the early research work, our team has carried out the related research on biodiesel. Therefore, the detailed biodiesel information can be obtained from references $[16,21]$.

2.5. Model and Validation. In order to validate the simulation result, the experiment had been carried out on the experimental bench of diesel engine. Horiba MEXA-1600 was used for measuring generated $\mathrm{NO}_{\mathrm{x}}$ with $1 \%$ error, while $\mathrm{AVL}$ Dismoke-4000 was employed for measuring generated soot. FCMM-2 was used for measuring the BFSC. DEWE2010CA was employed for monitoring the combustion of diesel engine. The list of measurements, the measuring range, and accuracy is shown in Table 4. In addition, an ECU control system was employed for controlling the electronically controlled diesel engine. EFS-IFR600 was employed for measuring fuel injection rate with $0.5 \%$ measuring error. A hydraulic dynamometer was used for measuring the diesel engine load. Moreover, the temperature, flow, and pressure

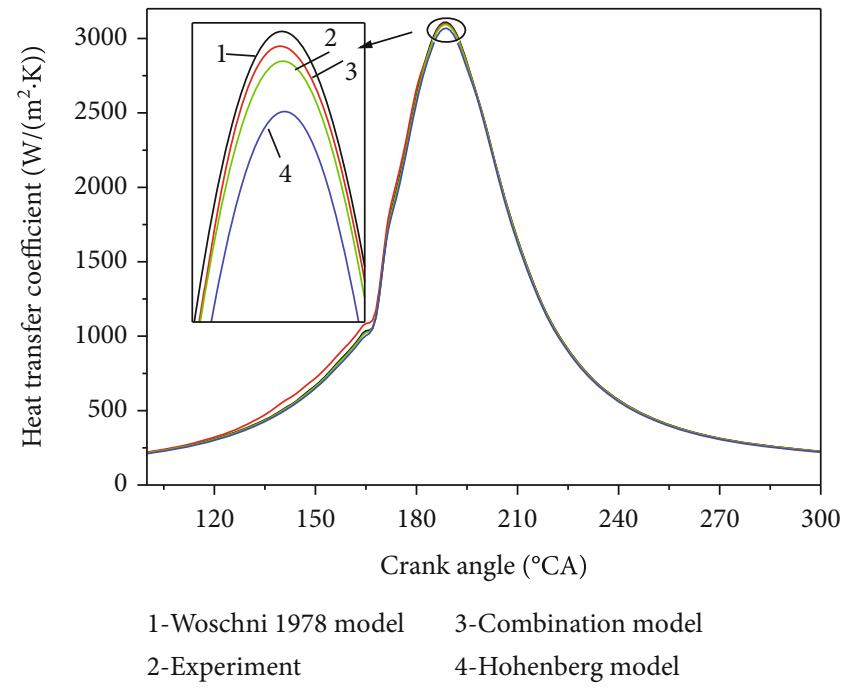

FIgURE 3: Heat transfer coefficient.

TABLE 5: Test cycle for different test points.

\begin{tabular}{|c|c|c|c|c|c|}
\hline Test cycle & Items & & Value & & \\
\hline \multirow{2}{*}{ D2 } & Engine speed (rpm) & & 1000 & & \\
\hline & Load & $100 \%$ & $50 \%$ & $25 \%$ & $10 \%$ \\
\hline \multirow{2}{*}{ E3 } & Engine speed (rpm) & 1000 & 911 & 799 & 628 \\
\hline & Power & $100 \%$ & $75 \%$ & $50 \%$ & $25 \%$ \\
\hline
\end{tabular}

were measured by suitable sensors. The schematics of experimental device are shown in Figure 2.

In the AVL-BOOST simulation environment, a fivecomponent biodiesel skeletal mechanism was employed to investigate the combustion process of biodiesel fuel consisting of 134 species and 475 reactions [46], the friction is 


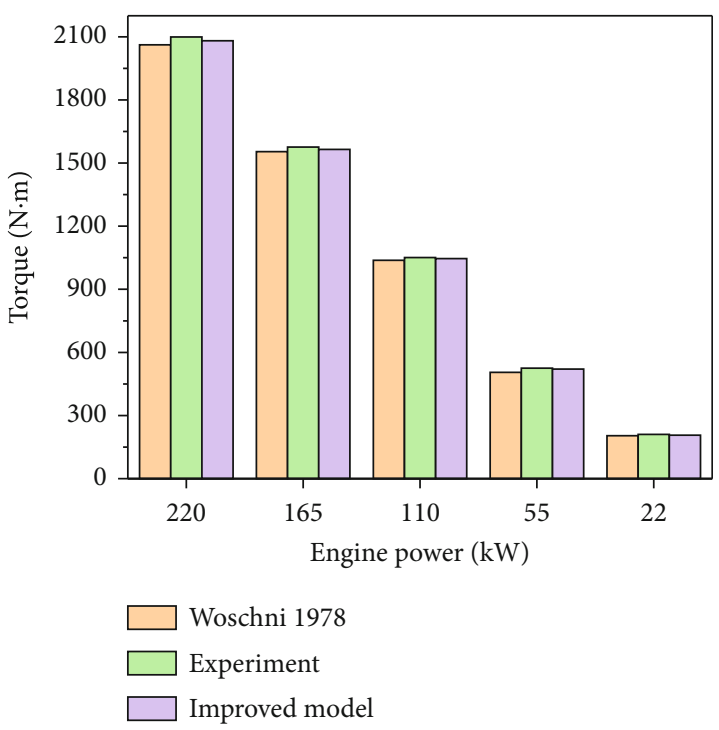

(a)

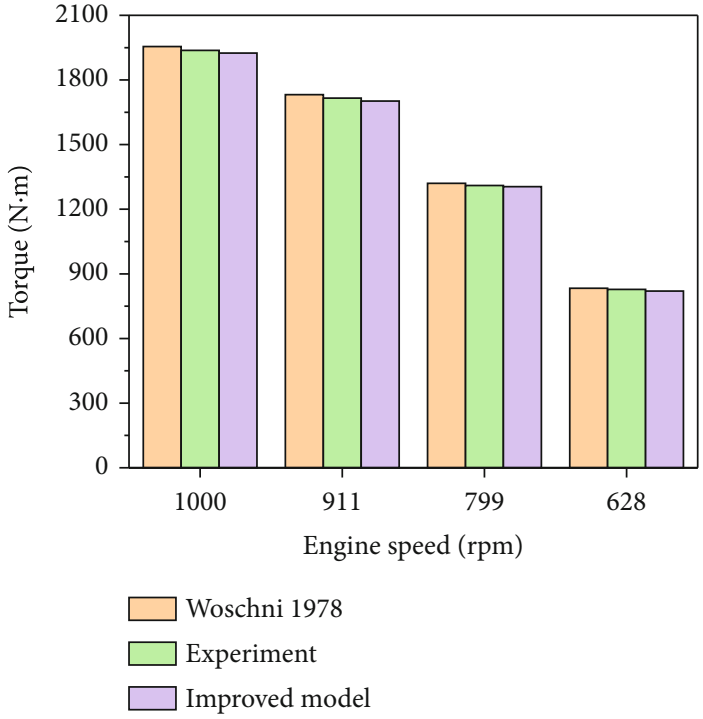

(b)

Figure 4: Variation of torque with different models.

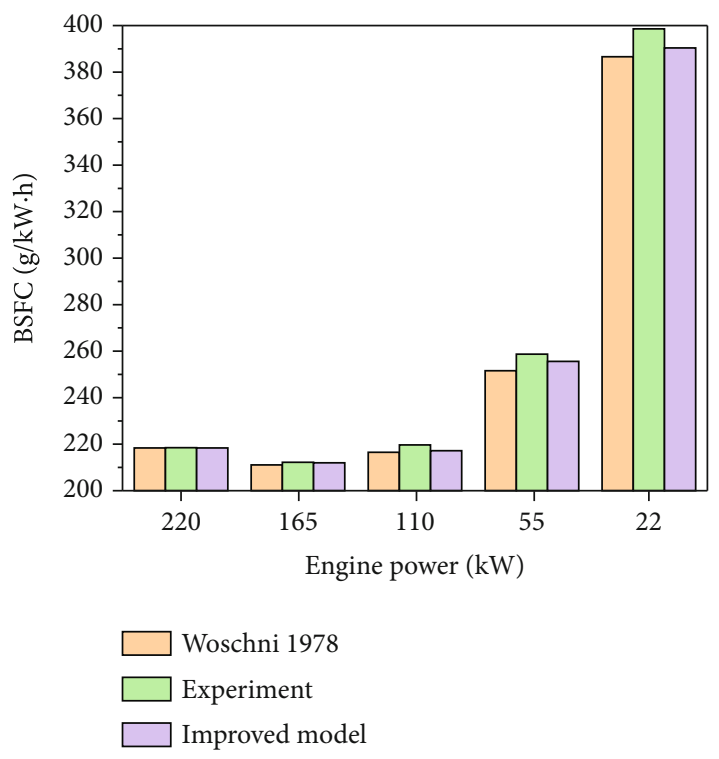

(a)

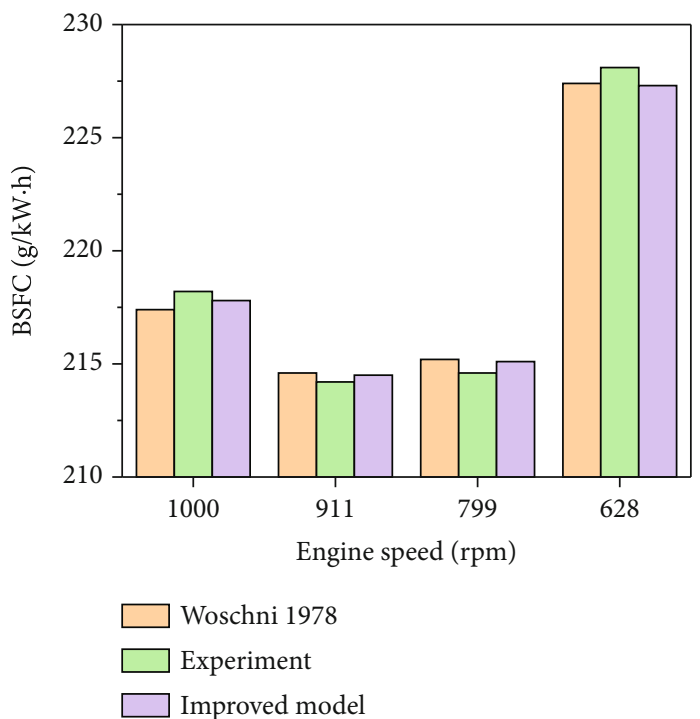

(b)

FIGURE 5: Variation of BSFC with different models.

calculated with the Chen-Flynn model, and the combustion in the cylinder is fitted with the AVL MCC combustion model $[47,48]$. The combustion model is effective to consider the influence of the jet kinetic energy and fuel injection rate on the instantaneous heat release and can accurately predict the formation of nitrogen oxides and soot. In addition, the combined heat transfer model, Woschni1978 heat transfer model, and Hohenberg heat transfer model are employed to simulate the heat transfer process in the cylinder, respectively.

In order to validate the combined model, the experiment was carried out and the comparisons of heat transfer coefficient are shown in Figure 3 at 100\% load. It can be found that predicted result of the combined model is in agreement with the experimental results. Through contrast experiment and correction, the predicted result of the combined model has the maximum error of $2.1 \%$, but the predicted result of the Woschni 1978 heat transfer model has the maximum error of $3.2 \%$. Thus, the combined model can better predict the performance characteristic of diesel engine.

\section{Results and Discussion}

The performance and emission characteristics of diesel engine and the effect of fuel injection rate on diesel engine fueled with RME were investigated. 


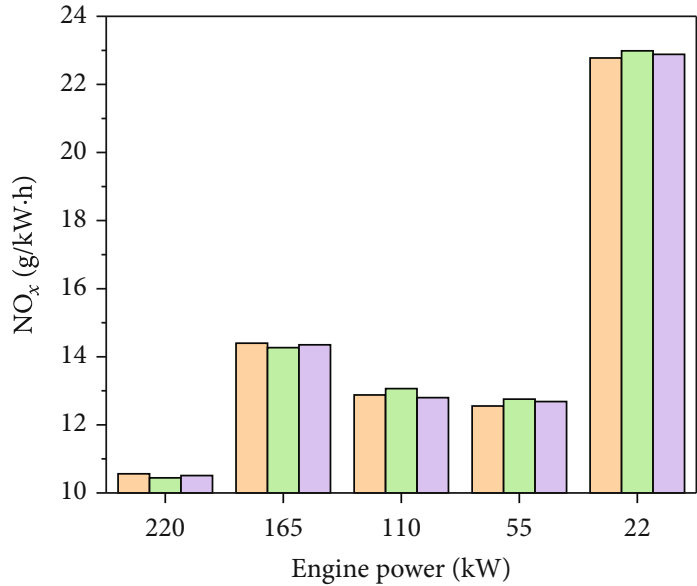

$\square$ Woschni 1978
$\square$ Experiment
$\square$ Improved model

(a)

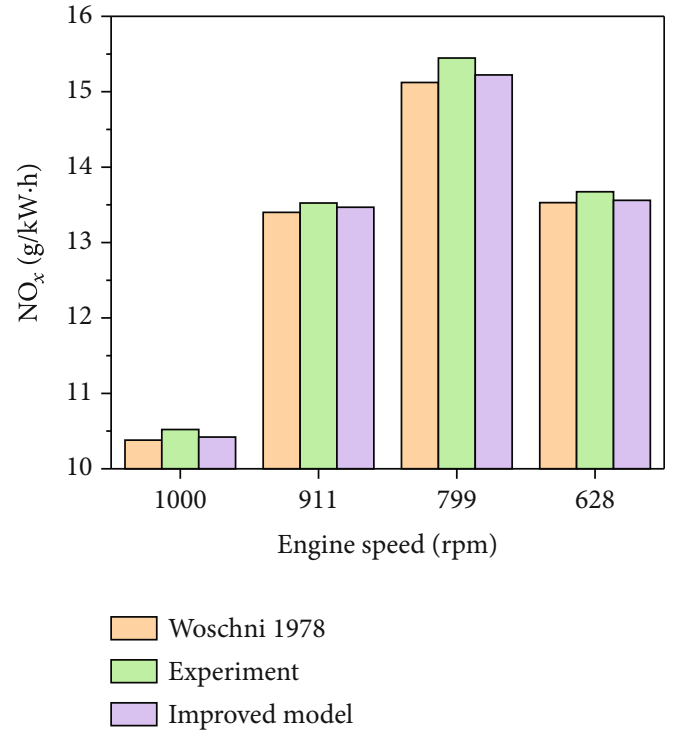

(b)

Figure 6: Variation of $\mathrm{NO}_{\mathrm{x}}$ emission with different models.

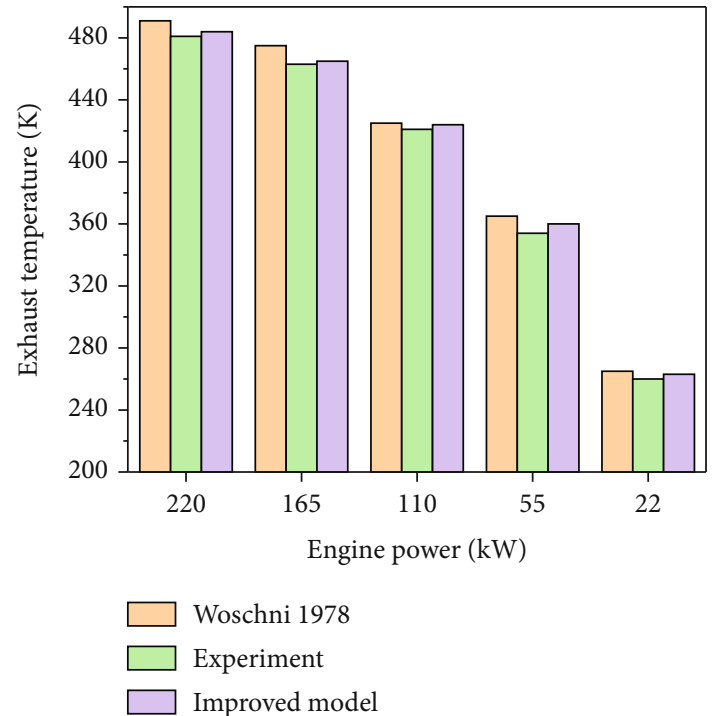

(a)

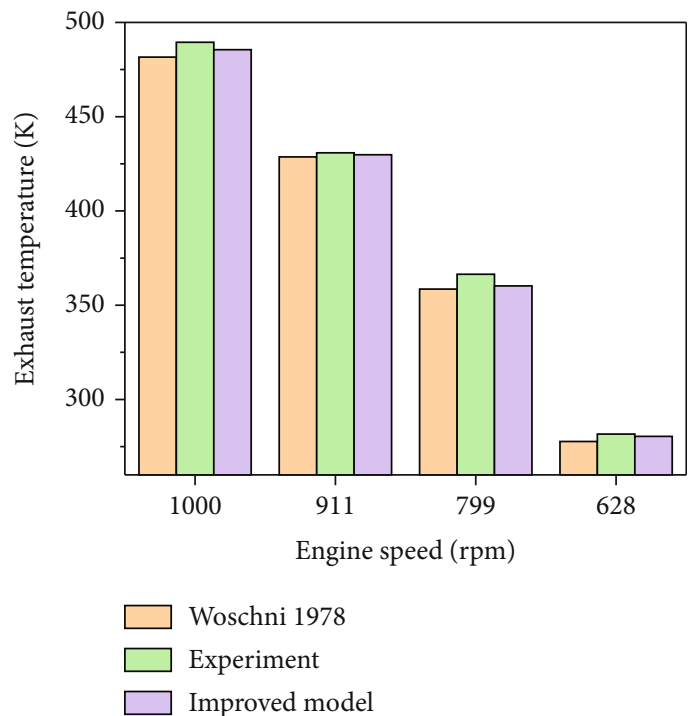

(b)

FIGURE 7: Variation of exhaust temperature with different models.

3.1. Load and Propulsion Characteristic of Diesel Engine. In the work, the diesel engine was performed at the E3 and D2 cycle modes in accordance with international ISO8178 standards. More specifically, the diesel engine was investigated at five different speeds $(628 \mathrm{rpm}, 710 \mathrm{rpm}, 799 \mathrm{rpm}, 911 \mathrm{rpm}$, and $1000 \mathrm{rpm}$ ), corresponding to $25 \%, 50 \%, 75 \%$, and $100 \%$ engine load. In addition, the diesel engine was operated at $25 \%, 50 \%, 75 \%$, and $100 \%$ engine loads when the engine speed is $1000 \mathrm{rpm}$. The E3 and D2 cycle modes for different test points are shown in Table 5. The improved heat transfer model and Woschni 1978 model are used to investigate the load and propulsion characteristics of diesel engine fueled with RME. The load and propulsion characteristics are discussed in the part in terms of torque, BSFC, temperature of behind the intercooler, $\mathrm{NO}_{\mathrm{x}}$ emission, and exhaust temperature.

3.1.1. Torque. The variation of torque with different models is shown in Figure 4. Figure 4(a) shows that the torque increases with the increase of power, torque is proportional with power, and all the points are on the same line. In addition, the result also shows that the torque can be calculated accurately by the numerical modes. More specifically, the maximum difference between the experimental result and predicted result calculated by the Woschni 1978 model is $3.8 \%$ and the maximum difference between the experimental result and predicted result calculated by the improved model reached $2.6 \%$. In addition, Figure $4(\mathrm{~b})$ shows that the torque 


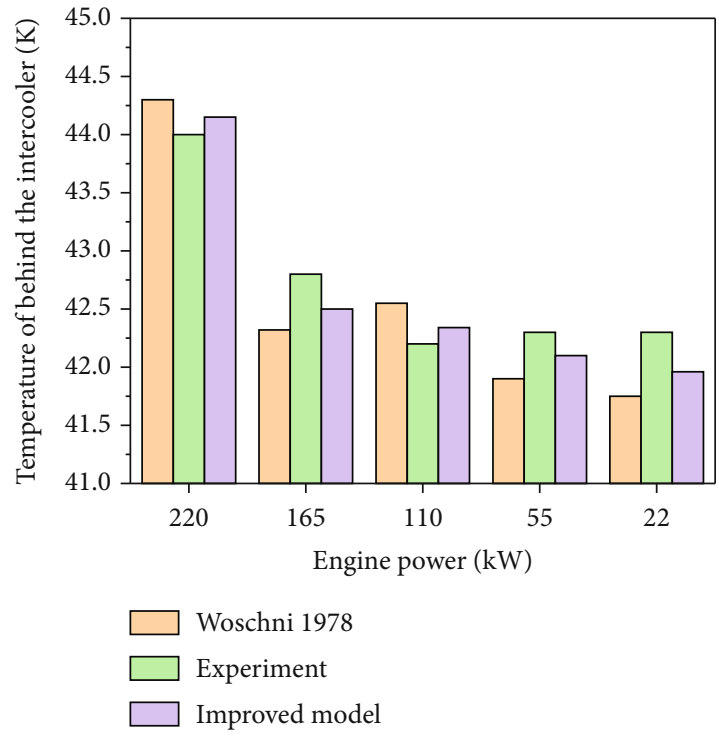

(a)

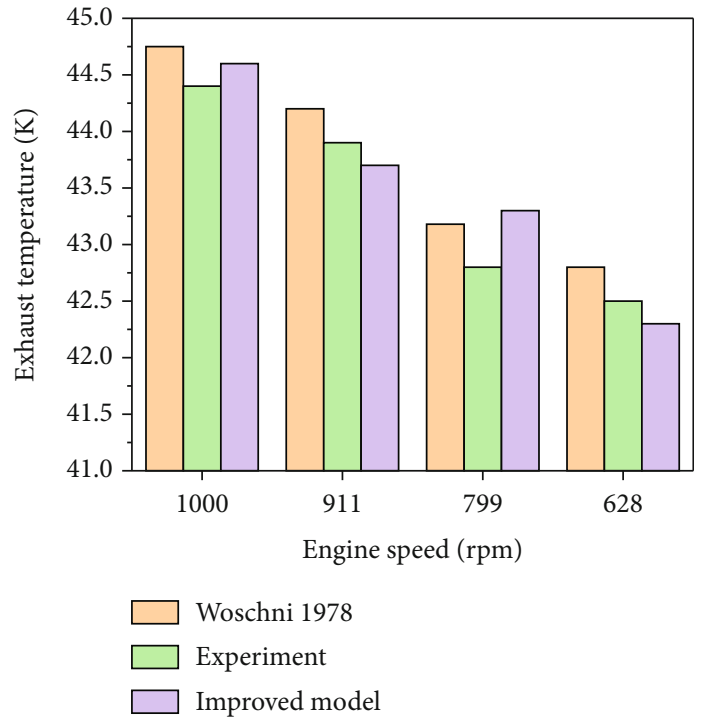

(b)

FIGURE 8: Variation of temperature of behind the intercooler with different models.

increases with the increase of engine speed. The improved model has higher accuracy. More specifically, the maximum difference between the experimental result and predicted result with the Woschni 1978 model is 3.5\% and the maximum difference between the experimental result and predicted result with the improved model reached $2.7 \%$. Thus, the improved combination model can better predict the torque of diesel engine.

3.1.2. Brake Specific Fuel Consumption. The variation of BSFC with different models is shown in Figure 5. Figure 5(a) shows that the BSFC firstly decreases and then increases with the increase of the power. In addition, the BSFC reached the minimum value at $75 \%$ engine load. Because the operating point of $75 \%$ engine load was the design operating point, the BSFC reached the minimum value at $75 \%$ load. Actually, the predicted results of the improved model have better accuracy compared with those of the Woschni 1978 model. More specifically, the maximum difference of BSFC between the experiment and the improved model is $2.8 \%$. In addition, the maximum difference between the experiment and Woschni 1978 model is $3.5 \%$. Figure 5(b) shows that the BSFC firstly decreases and then increases with the increase of the engine speed. Between $799 \mathrm{rpm}$ and $910 \mathrm{rpm}$, the BFSC is lower than the other operating points. The BSFC reaches the minimum value at $75 \%$ engine load. It is due to the fact that the operating point is the design operating point. Therefore, the efficiency is relatively large. In addition, it can also be found that the improved model can better predict the BSFC and the maximum difference between improved model and experiment is slightly lower than the maximum difference between the experiment and Woschni 1978 model.

3.1.3. $N O_{x}$ Emission. The variation of BSFC with different models is shown in Figure 6. Figure 6(a) shows that the
TABLE 6: Work cases.

\begin{tabular}{lccccc}
\hline Cases & $\begin{array}{c}\text { High- } \\
\text { pressure oil } \\
\text { pipe length } \\
(\mathrm{mm})\end{array}$ & $\begin{array}{c}\text { Injector } \\
\text { orifice } \\
\text { diameter } \\
(\mathrm{mm})\end{array}$ & $\begin{array}{c}\text { Plunger } \\
\text { diameter } \\
(\mathrm{mm})\end{array}$ & $\begin{array}{c}\text { Injection } \\
\text { duration } \\
\text { angle }\left(^{\circ}\right)\end{array}$ & $\begin{array}{c}\text { Injection } \\
\text { pressure } \\
(\mathrm{MPa})\end{array}$ \\
\hline $\begin{array}{l}\text { Case } \\
1\end{array}$ & 850 & 0.24 & 14.0 & 33.4 & 100.944 \\
$\begin{array}{l}\text { Case } \\
2\end{array}$ & 850 & 0.24 & 14.5 & 32.9 & 108.377 \\
$\begin{array}{l}\text { Case } \\
3\end{array}$ & 850 & 0.26 & 14.5 & 32.5 & 100.700 \\
$\begin{array}{l}\text { Case } \\
4\end{array}$ & 900 & 0.24 & 14.0 & 33.6 & 100.604 \\
Case & 900 & 0.24 & 14.5 & 33.1 & 108.267 \\
5 & & & & & \\
\hline
\end{tabular}

$\mathrm{NO}_{\mathrm{x}}$ emission firstly decreases, then increases and finally decreases with the increased engine power. The $\mathrm{NO}_{\mathrm{x}}$ emission increases with the increasing power, but the increase of power is slower than the increase of $\mathrm{NO}_{\mathrm{x}}$ emission. Thus, the $\mathrm{NO}_{\mathrm{x}}$ emission per unit power increases. When the load is higher than $75 \%$, the $\mathrm{NO}_{\mathrm{x}}$ emission deceases. It is due to the fact that combustion is deteriorated by the increased fuel. In addition, Figure 6(b) shows that the $\mathrm{NO}_{\mathrm{x}}$ emission firstly increases and then decreases with the increased engine speed. It is due to the higher cylinder temperature caused by fuel injection mass. When the speed is higher than $799 \mathrm{rpm}$, the effects of high cylinder temperature would be dominated by the impact of the decreased oxygen content. Thus, the $\mathrm{NO}_{\mathrm{x}}$ emission per unit power decreases. It also can be found that the improved combination model can better predict the $\mathrm{NO}_{\mathrm{x}}$ emission.

3.1.4. Exhaust Temperature. The variation of exhaust temperature with different models is shown in Figure 7. 


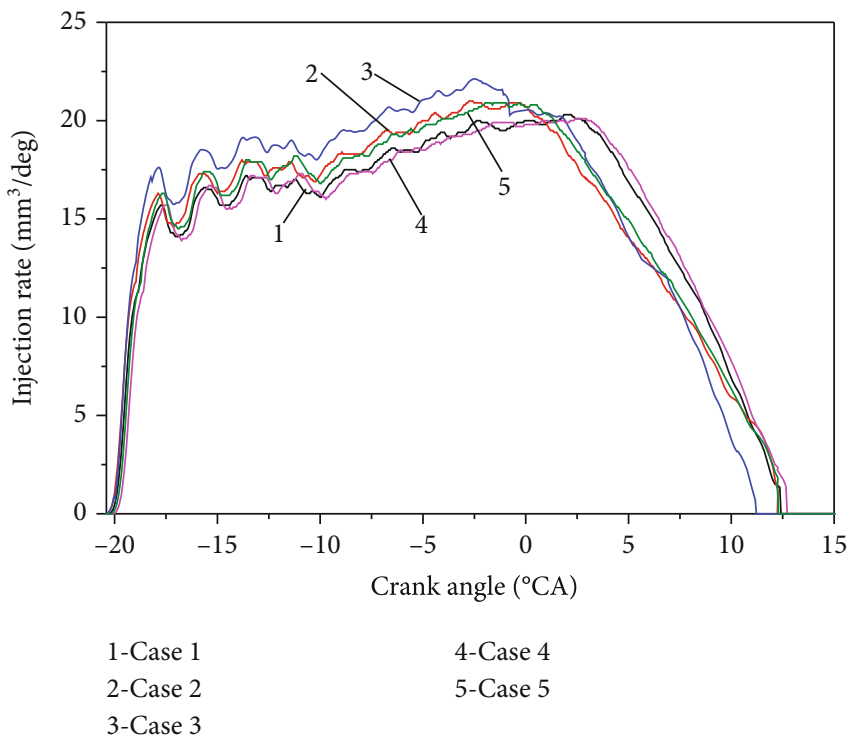

Figure 9: Fuel injection rate with constant fuel injection mass.

Figure 7 (a) shows that the exhaust temperature increases with the increase of the engine power. It is due to the fact that the increased fuel injection mass results in the increase of engine load. Similarly, the maximum difference between the experiment and the improved model is slightly lower than the maximum difference between the experiment and Woschni 1978 model. In addition, Figure 7(b) shows that the exhaust temperature increases with the increase of the engine speed. The engine load increases with the increase of speed, then results in the increase of exhaust temperature. It can also be found that the improved model can better compute the temperature. Thus, the improved combination model can better predict the exhaust temperature.

3.1.5. Temperature of behind the Intercooler. The variation of temperature of behind the intercooler with different models is shown in Figure 8. Figure 8(a) shows that the temperature of behind the intercooler increases with the increase of the engine power. In addition, Figure 8(b) shows that the temperature of behind the intercooler increases with the increase of the engine speed. The main reason is that the increase of load leads to the increase of combustion temperature, which increases the cooling load. It can also be found that the improved model can better compute the temperature. More specifically, the maximum difference between the experiment and the improved model is slightly lower than the maximum difference between the experiment and Woschni 1978 model.

As mentioned, the Woschni 1978 model and improved model also can better predict the propulsion and load characteristics of diesel engine. However, the improved model is more accurate in prediction. It is due to the fact that the advantages of the two models are combined.

3.2. Fuel Inject Rate. In order to optimize and match the structural parameters of the inject system, the engine is carried out at $1000 \mathrm{rpm}$ and the fuel injection mass remains constant in the experiment. Four parameters were considered mainly in this work. To further investigate deeply the detailed optimized planning, the experiments were carried out by changing the plunger diameter from $13 \mathrm{~mm}$ to $14.5 \mathrm{~mm}$ (4 levels), the injection orifice diameter from $0.22 \mathrm{~mm}$ to $0.28 \mathrm{~mm}$ (4 levels), the length of high-pressure oil pipe from 850 to 900 (2 levels), and the cam profile velocity from $0.43 \mathrm{~mm} /{ }^{\circ}$ to $0.46 \mathrm{~mm} /{ }^{\circ}$ (2 levels).

The measurement precision and calibration of fuel inject rate are very essential to analyze the formation of mixed gas and combustion processes in the engine cylinder. In order to improve the combustion, the high-pressure oil pipe, injector orifice, plunger diameter, injection duration angle, and injection pressure should be considered in the paper. The injection duration is less than $35^{\circ} \mathrm{CA}$, and the injection pressure is greater than $100 \mathrm{MPa}$. According to the advanced plan, five cases were selected and were employed to investigate the effects of variable injection rates on the engine characteristic in the paper.

The five cases selected are shown in Table 6, and the fuel injection rates are shown in Figure 9. It can be found that the effect of the length of high-pressure oil pipe on injection rate is insignificant and the injection pressure decreases with the increase of length of the high-pressure oil pipe in Table 5. It is due to the increased resistances caused by the increased length of the high-pressure pipe. In addition, Figure 9 shows that the fuel injection rate and the injection pressure increase with the increased of the diameter of the plunger when the fuel injection mass keeps constant. The injection duration angle decreases with the increase of the diameter of the plunger. However, the injection pressure and injection duration angle decrease with the increase of the injector orifice diameter. Injector orifice diameter and diameter of plunger are significant to fuel injection rate.

The improved heat transfer model is used to investigate the effect of fuel injection rate on the engine characteristic of diesel engine fueled with RME in terms of cylinder pressure, heat release rate, soot emission, $\mathrm{NO}_{\mathrm{x}}$ emission, and 


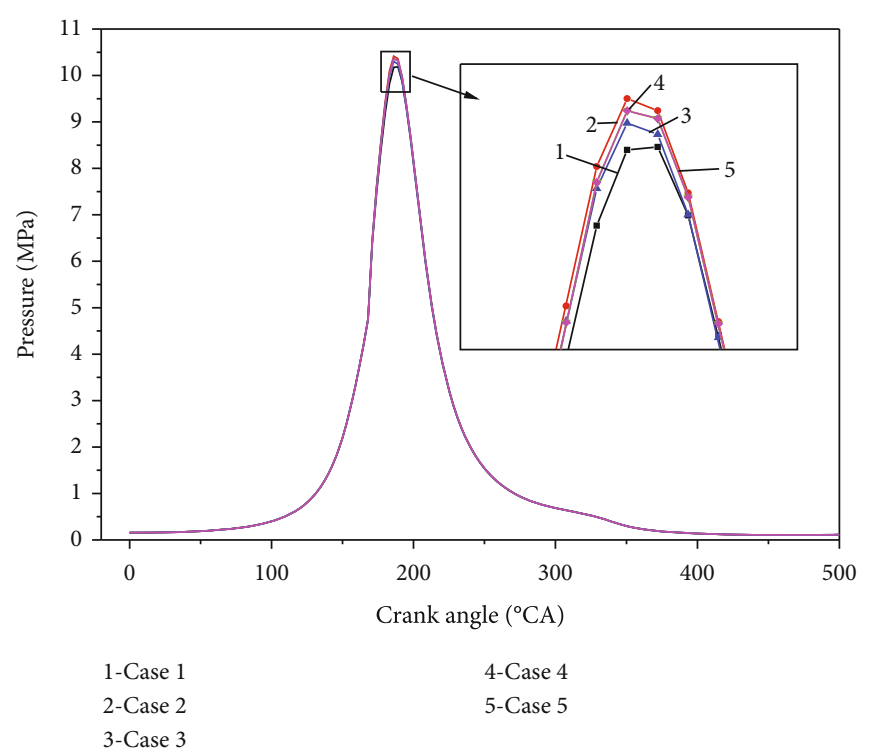

(a)

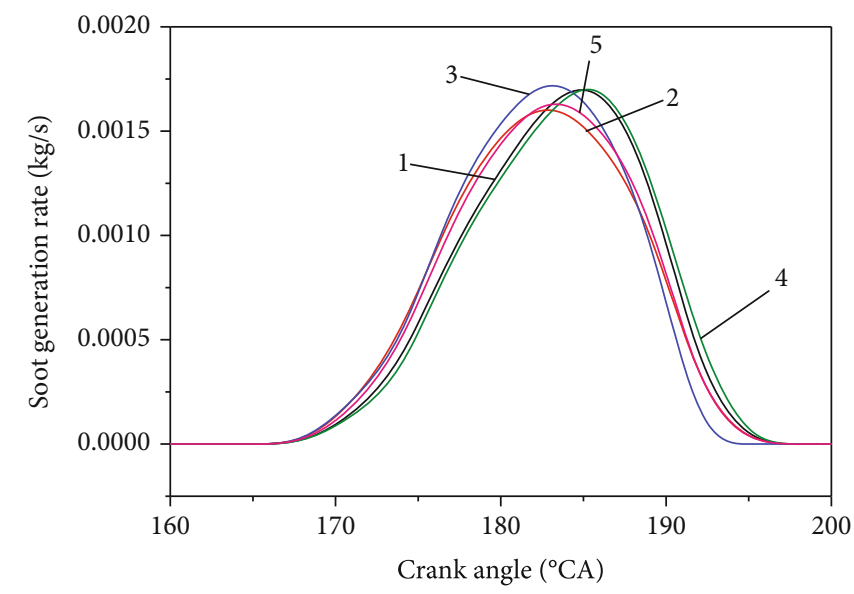

1-Case 1

2-Case 2

3-Case 3

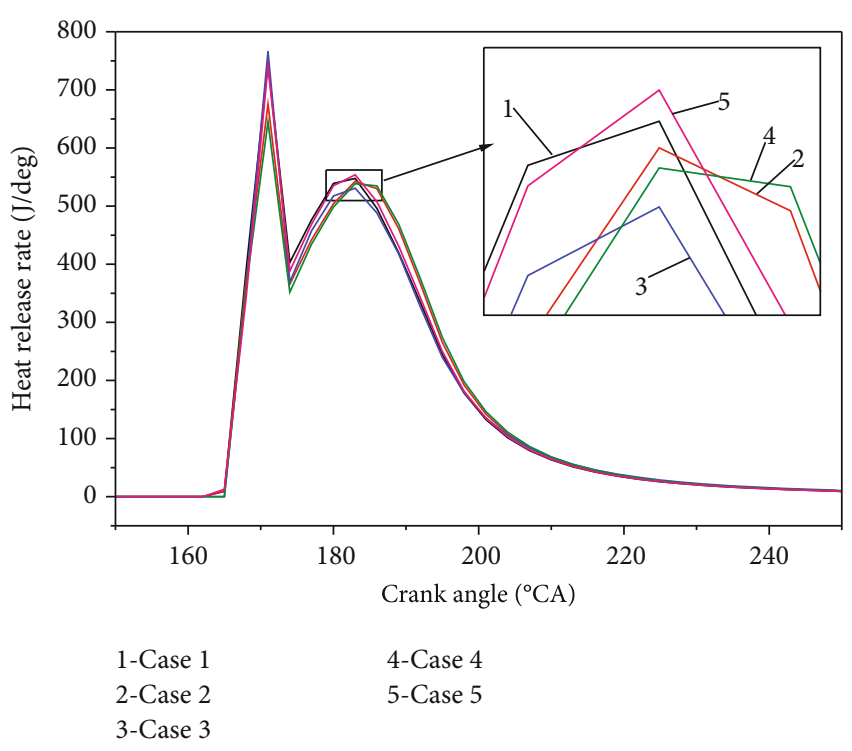

(b)

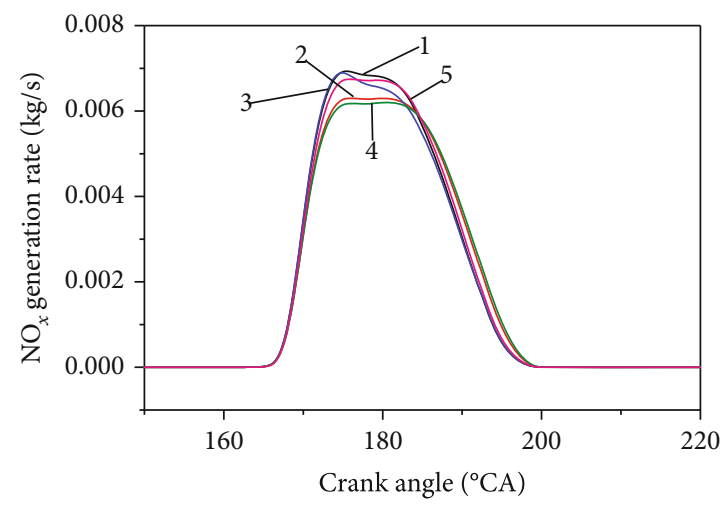

1-Case 1

2-Case 2

3-Case 3

5-Case 5

(d)

(c)

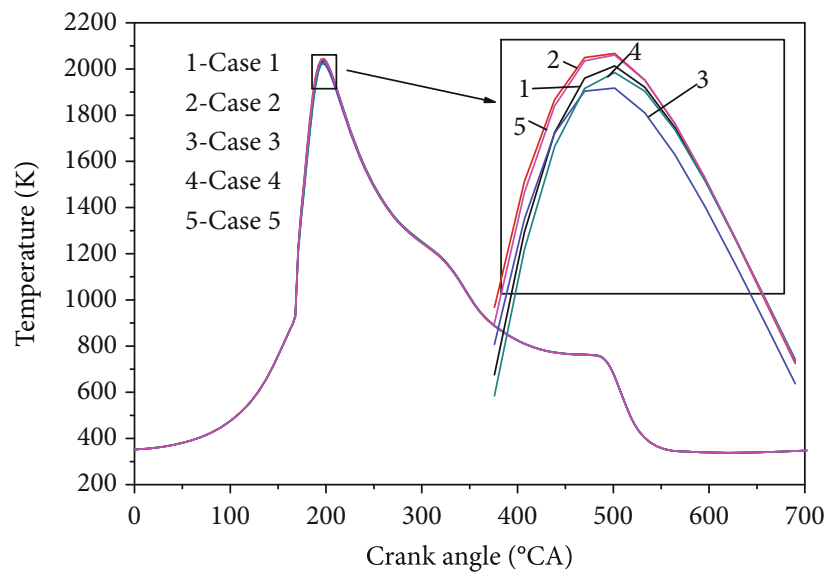

(e)

FIGURE 10: Effect of injection rate on diesel engine. 

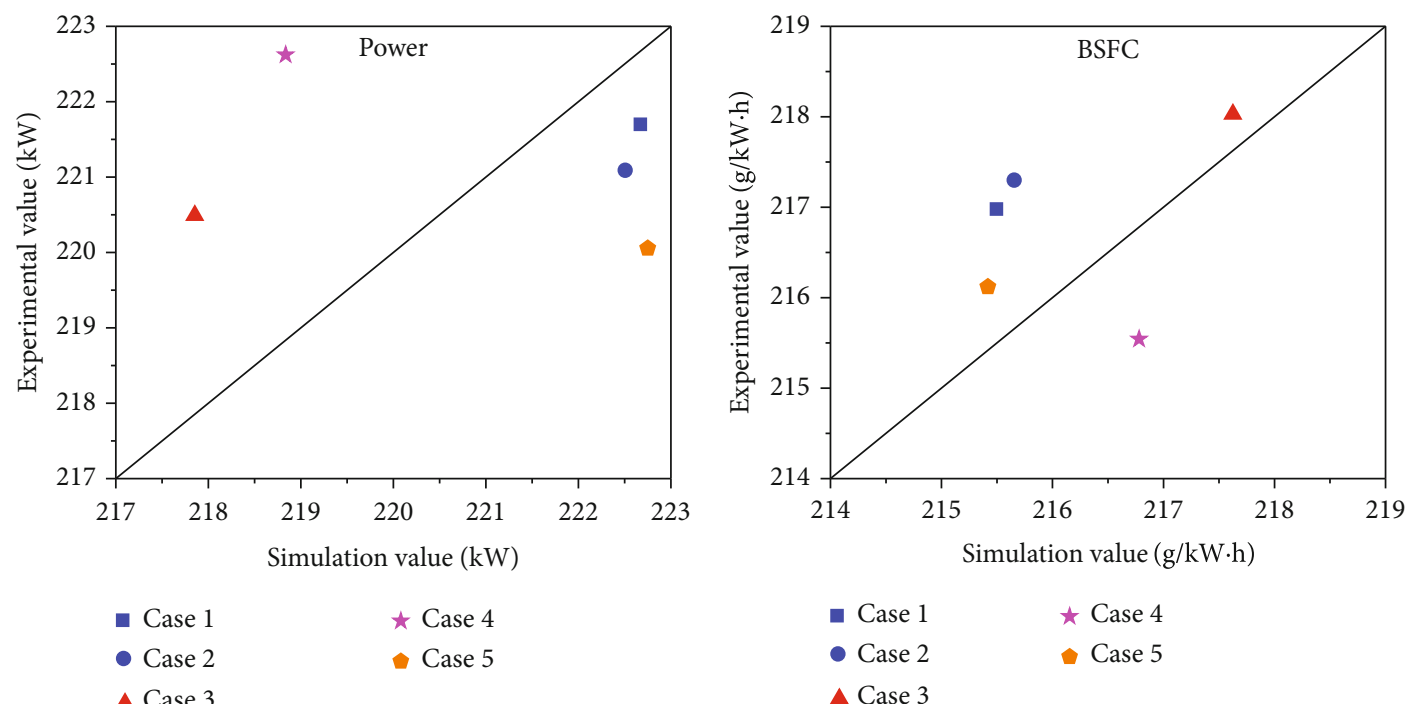

(a) Power

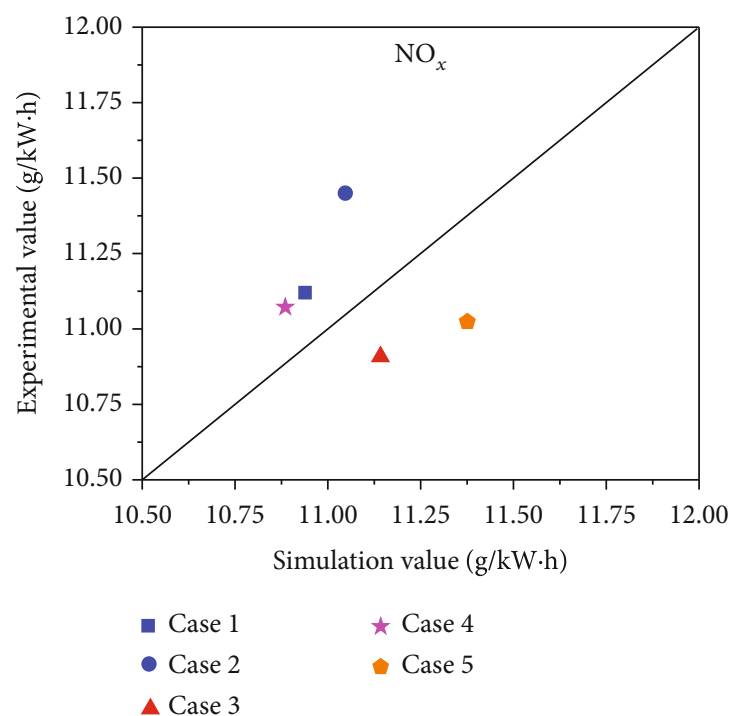

(c) $\mathrm{NO}_{\mathrm{x}}$ (b) BSFC

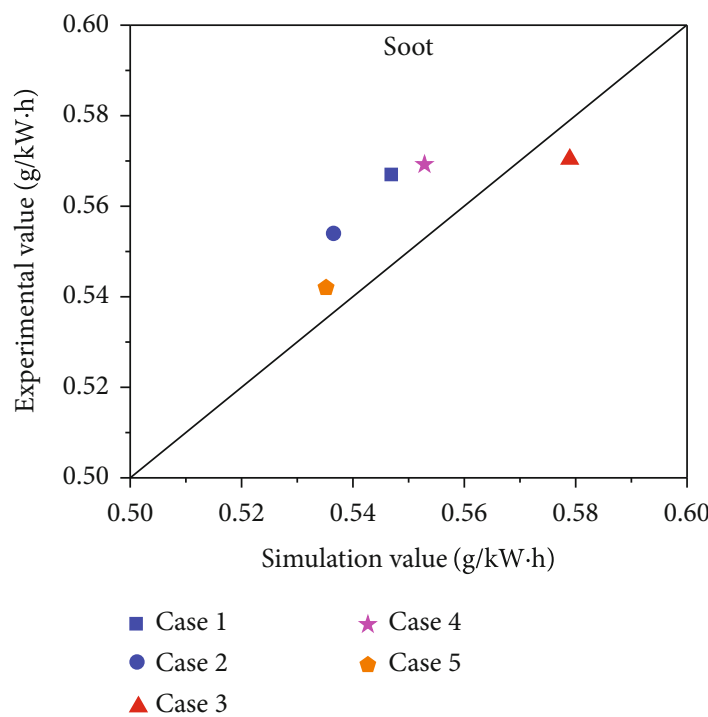

(d) Soot

Figure 11: Comparison of the simulation results with constant fuel injection mass.

cylinder temperature. In the experiment, the engine speed is $1000 \mathrm{rpm}$ and the fuel injection mass remains constant.

As shown in Figure 10(a), the cylinder pressure of case 2 is the highest. It is due to the fact that the fuel atomization and cylinder combustion are improved by the high fuel injection pressure. In addition, the maximum peak pressure corresponding to the lower due to the delayed injection pressure and the time to reach the peak pressure also have a certain delay. As shown in Figure 10(b), as the fuel injection rate is larger, the heat release rate is larger at an early stage. It is due to the larger injector orifice diameter. The smaller the fuel injection pressure, the greater the fuel injection map, the longer the delay of heat release rate.

As shown in Figure 10(c), the soot generation rate of case 3 is the first to reach the peak. The injector orifice diameter is larger so that the injection pressure becomes lower. Finally, the fuel atomization becomes worse. Therefore, case 3 gener- ates the most soot emission, followed by case 1 and case 4 . As shown in Figure $10(\mathrm{~d})$, the $\mathrm{NO}_{\mathrm{x}}$ generation rate of case 4 is the minimum and the $\mathrm{NO}_{\mathrm{x}}$ generation rate of case 3 is the maximum. The high cylinder temperature is the important parameter, resulting in the $\mathrm{NO}_{\mathrm{x}}$ generation. In the early stage, a large amount of fuel is injected into the cylinder in case 3 . In addition, the fuel injection pressure is low so that the fuel atomization is relatively bad. It is easy to form the local high temperature area in case 3 . Thus, the $\mathrm{NO}_{\mathrm{x}}$ generation rate of case 3 is the maximum. It can be found that the curve of $\mathrm{NO}_{\mathrm{x}}$ generation is delayed with the decrease of fuel injection rate and $\mathrm{NO}_{\mathrm{x}}$ generation value is in turn to reach the maximum value.

As shown in Figure 10(e), due to the high fuel injection pressure and fine atomization, the peak in-cylinder temperature of case 2 is the highest, followed by case 5 . The faster the fuel pressure is built, the faster the temperature will reach the 
maximum value. In other words, with the delay of building pressure time, the peak in-cylinder temperature is also delayed. The fuel injection pressure and atomization effect of fuel have the most efficient influence on the cylinder temperature.

3.3. Experimental Verification. In the experimental process, the engine speed is $1000 \mathrm{rpm}$ and the fuel injection mass remains constant. The engine characteristic of diesel engine fueled with RME is investigated in terms of power, BSFC, $\mathrm{NO}_{\mathrm{x}}$ emission, and soot emission. Figure 11 shows the comparisons of the simulation and experiment results. It can be found that the error between the experiment result and simulation result is less than $2 \%$. Thus, the simulation model can accurately forecast the trend of the engine characteristic.

The BFSC and soot are the minimum, and the effective power of case 5 is the maximum. More specifically, compared with case $4, \mathrm{NO}_{\mathrm{x}}$ emission was more than $0.94 \%$, but the soot was reduced by $5 \%$, and BFSC decreased by $0.42 \%$ in case 5 . In addition, it can be found that the economy is worst in case 3. The $\mathrm{NO}_{\mathrm{x}}$ emission is the least in case 4. The efficiency power and torque are relatively large, and the formations of BFSC and soot are the least in case 5. Compared with case 3 , the effective power and the effective torque are increased by $1.02 \%$ and $1.023 \%$, respectively; the soot formation decreased by $7.4 \%$, but the nitrogen oxides only increased by $1.1 \%$ in case 5 . Based on an overall consideration of various factors, case 5 is the most reasonable. Therefore, it is very important to choose the injection rate reasonably. The big inject orifice is not beneficial to the fuel atomization, and more soot is produced.

\section{Conclusion}

Nowadays, the energy crisis [49-56] and environmental pollution [55-61] are more and more serious accompanied by global economic development and manufacturing production. How to improve the combustion efficiency of diesel engine and reduce harmful gas emission of diesel engine is a very important work. In the work, an improved heat transfer model in the cylinder was developed in the AVL-BOOST environment. The corresponding entirety model was performed by AVL-BOOST coupled CHEMKINII code which consists of 475 reactions and 134 species, then validated by the experiment. Finally, the propulsion and load characteristics of diesel engine fueled with biodiesel fuel were simulated by the improved heat transfer model. In addition, the effect of fuel injection rate on the engine characteristic of diesel engine fueled with RME was investigated in terms of exhaust temperature, BSFC, soot, and $\mathrm{NO}_{\mathrm{x}}$ emission. The main conclusions are as follows:

(1) Compared with the Woschni 1978 model, the improved model is more accurate in prediction. The maximum difference between the experiment and Woschni 1978 model is reduced. It is due to the fact that the improved model combines the advantages of the two models
(2) The higher engine power will increase the effective torque, exhaust temperature, and temperature of behind the intercooler. More specifically, the calculated results are very similar and the maximum difference between the experiment and the improved model is lower than the maximum difference between the experiment and the Woschni 1978 model

(3) Compared with case 3, the effective power and the effective torque are increased by $1.02 \%$ and $1.023 \%$, respectively; the soot emission decreased by $7.4 \%$, but the nitrogen oxides only increased by $1.1 \%$ in case 5 . Based on an overall consideration of various factors, case 5 is the most reasonable

\section{Data Availability}

All data used to support the findings of this study are included within the article.

\section{Conflicts of Interest}

The authors declare that there are no conflicts of interest regarding the publication of this article.

\section{Acknowledgments}

This work is supported by the Natural Science Foundation of Guangxi under the research grant 2018GXNSFAA281267, the Guangxi Young and middle-aged college Teachers Basic Research Ability Promotion Project under the research grant 2020KY39008, and the Key Scientific Research Projects of Guangxi Vocational \& Technical Institute of Industry under the research grant $2019015 \mathrm{KY} 025$.

\section{References}

[1] D. Zhao, C. Ji, X. Li, and S. Li, "Mitigation of premixed flamesustained thermoacoustic oscillations using an electrical heater," International Journal of Heat \& Mass Transfer, vol. 86, pp. 309-318, 2015.

[2] E. Jiaqiang, G. Liu, Z. Zhang et al., "Effect analysis on cold starting performance enhancement of a diesel engine fueled with biodiesel fuel based on an improved thermodynamic model," Applied Energy, vol. 243, pp. 321-335, 2019.

[3] E. Jiaqiang, X. Zhao, G. Liu et al., "Effects analysis on optimal microwave energy consumption in the heating process of composite regeneration for the diesel particulate filter," Applied Energy, vol. 254, article 113736, 2019.

[4] B. Zhang, E. Jiaqiang, J. Gong, W. Yuan, X. Zhao, and W. Hu, "Influence of structural and operating factors on performance degradation of the diesel particulate filter based on composite regeneration," Applied Thermal Engineering, vol. 121, pp. 838852, 2017.

[5] B. Wang, J. Xu, R. J. Wai, and B. Cao, "Adaptive sliding-mode with hysteresis control strategy for simple multimode hybrid energy storage system in electric vehicles," IEEE Transactions on Industrial Electronics, vol. 64, no. 2, pp. 1404-1414, 2017.

[6] G. Wu, Z. Lu, X. Xu et al., "Numerical investigation of aeroacoustics damping performance of a Helmholtz resonator: 
effects of geometry, grazing and bias flow," Aerospace Science and Technology, vol. 86, pp. 191-203, 2019.

[7] D. Han, E. Jiaqiang, Y. Deng et al., "A review of studies using hydrocarbon adsorption material for reducing hydrocarbon emissions from cold start of gasoline engine," Renewable \& Sustainable Energy Reviews, vol. 135, p. 110079, 2021.

[8] B. Wang, J. Xu, B. Cao, and X. Zhou, "A novel multimode hybrid energy storage system and its energy management strategy for electric vehicles," Journal of Power Sources, vol. 281, pp. 432-443, 2015.

[9] G. Wu, Z. Lu, W. Pan, Y. Guan, S. Li, and C. Ji, "Experimental demonstration of mitigating self-excited combustion oscillations using an electrical heater," Applied Energy, vol. 239, pp. 331-342, 2019.

[10] E. Jiaqiang, M. Pham, D. Zhao et al., "Effect of different technologies on combustion and emissions of the diesel engine fueled with biodiesel: a review," Renewable and Sustainable Energy Reviews, vol. 80, pp. 620-647, 2017.

[11] E. Jiaqiang, Z. Zhang, J. Chen et al., "Performance and emission evaluation of a marine diesel engine fueled by water biodiesel-diesel emulsion blends with a fuel additive of a cerium oxide nanoparticle," Energy Conversion and Management, vol. 169, pp. 194-205, 2018.

[12] E. Jiaqiang, M. Liu, Y. Deng, H. Zhu, and J. Gong, "Influence analysis of monolith structure on regeneration temperature in the process of microwave regeneration in the diesel particulate filter," Canadian Journal of Chemical Engineering, vol. 94, no. 1, pp. 168-174, 2016.

[13] E. Jiaqiang, X. Zhao, L. Qiu et al., "Experimental investigation on performance and economy characteristics of a diesel engine with variable nozzle turbocharger and its application in urban bus," Energy Conversion and Management, vol. 193, pp. 149-161, 2019.

[14] T. Liu, E. Jiaqiang, W. Yang, A. Hui, and H. Cai, “Development of a skeletal mechanism for biodiesel blend surrogates with varying fatty acid methyl esters proportion," Applied Energy, vol. 162 , pp. $278-288,2016$.

[15] Z. Zhang, E. Jiaqiang, Y. Deng et al., "Effects of fatty acid methyl esters proportion on combustion and emission characteristics of a biodiesel fueled marine diesel engine," Energy Conversion \& Management, vol. 159, pp. 244-253, 2018.

[16] T. Liu, E. Jiaqiang, W. M. Yang et al., "Investigation on the applicability for reaction rates adjustment of the optimized biodiesel skeletal mechanism," Energy, vol. 150, pp. 10311038, 2018.

[17] Ö. Can, "Combustion characteristics, performance and exhaust emissions of a diesel engine fueled with a waste cooking oil biodiesel mixture," Energy Conversion and Management, vol. 87, pp. 676-686, 2014.

[18] O. Özener, L. Yüksek, A. T. Ergenç, and M. Özkan, "Effects of soybean biodiesel on a DI diesel engine performance, emission and combustion characteristics," Fuel, vol. 115, pp. 875-883, 2014.

[19] H. K. Imdadul, H. H. Masjuki, M. A. Kalam et al., "Higher alcohol-biodiesel-diesel blends: an approach for improving the performance, emission, and combustion of a light-duty diesel engine," Energy Conversion and Management, vol. 111, pp. 174-185, 2016.

[20] Y. Deng, H. Liu, X. Zhao, E. Jiaqiang, and J. Chen, "Effects of cold start control strategy on cold start performance of the diesel engine based on a comprehensive preheat diesel engine model," Applied Energy, vol. 210, pp. 279-287, 2018.
[21] E. Jiaqiang, M. Pham, Y. Deng et al., "Effects of injection timing and injection pressure on performance and exhaust emissions of a common rail diesel engine fueled by various concentrations of fish-oil biodiesel blends," Energy, vol. 149, pp. 979-989, 2018.

[22] Z. W. Meng, C. Chen, J. S. Li et al., "Particle emission characteristics of DPF regeneration from DPF regeneration bench and diesel engine bench measurements," Fuel, vol. 262, p. 116589, 2020.

[23] Z. W. Meng, J. S. Li, J. Fang et al., "Experimental study on regeneration performance and particle emission characteristics of DPF with different inlet transition sections lengths," Fuel, vol. 262, p. 116487, 2020.

[24] P. Wang, J. Yi, C. Sun, P. Luo, and L. L. Lei, "Evaluation of $\mathrm{H}_{2}$ influence on the evolution mechanism of NOx storage and reduction over $\mathrm{Pt}-\mathrm{Ba}-\mathrm{Ce} / \gamma-\mathrm{Al}_{2} \mathrm{O}_{3}$ catalysts," Engineering, vol. 5, no. 3, pp. 568-575, 2019.

[25] P. Wang, D. Yu, G. Wu, F. Sheikh, and J. Liu, " $\mathrm{NO}_{\mathrm{x}}$ adsorption and desorption of a Mn-incorporated NSR catalyst $\mathrm{Pt} / \mathrm{Ba} /-$ $\mathrm{Ce} / \mathrm{xMn} / \gamma-\mathrm{Al}_{2} \mathrm{O}_{3}$," Environmental Science and Pollution Research, vol. 26, pp. 27888-27896, 2019.

[26] H. Xu, S. Liu, Y. Wang, Q. Lin, and Y. Chen, "Promotional effect of $\mathrm{Al}_{2} \mathrm{O}_{3}$ on $\mathrm{WO}_{3} / \mathrm{CeO}_{2}-\mathrm{ZrO}_{2}$ monolithic catalyst for selective catalytic reduction of nitrogen oxides with ammonia after hydrothermal aging treatment," Applied Surface Science, vol. 427, pp. 656-669, 2018.

[27] Z. Zhang, E. Jiaqiang, J. W. Chen et al., "Effects of boiling heat transfer on the performance enhancement of a medium speed diesel engine fueled with diesel and rapeseed methyl ester," Applied Thermal Engineering, vol. 169, p. 114984, 2020.

[28] P. Lino, B. Maione, and A. Rizzo, "Nonlinear modelling and control of a common rail injection system for diesel engines," Applied Mathematical Modelling, vol. 31, no. 9, pp. 17701784, 2007.

[29] T. Lähde, T. Rönkkö, M. Happonen et al., "Effect of fuel injection pressure on a heavy-duty diesel engine nonvolatile particle emission," Environmental Science \& Technology, vol. 45, no. 6, pp. 2504-2509, 2011.

[30] G. Wu, Z. L. Li, S. Abubakar, Y. L. Li, and Y. Li, "Numerical study on effects of key factors on performance of $\mathrm{CeO}_{2}$-based catalyzed diesel particulate filter," Journal of Thermal Science, vol. 29, no. 6, pp. 1398-1409, 2020.

[31] E. Frosina, A. Senatore, D. Buono, and L. Arnone, "A critical analysis on the lubrication circuit of a non-road diesel engine by adopting a 3D and 1D approaches," Energy Procedia, vol. 81, pp. 794-804, 2015.

[32] I. R. Fattah, H. H. Masjuki, M. A. Kalam, M. A. Wakil, A. M. Ashraful, and S. A. Shahir, "Experimental investigation of performance and regulated emissions of a diesel engine with Calophyllum inophyllum biodiesel blends accompanied by oxidation inhibitors," Energy Conversion and Management, vol. 83, pp. 232-240, 2014.

[33] M. H. Mosarof, M. A. Kalam, H. H. Masjuki et al., "Implementation of palm biodiesel based on economic aspects, performance, emission, and wear characteristics," Energy Conversion and Management, vol. 105, pp. 617-629, 2015.

[34] Q. Zuo, Y. Xie, Q. Guan et al., "Effect of critical dual-carrier structure parameters on performance enhancement of a dual-carrier catalytic converter and the gasoline engine system," Energy Conversion \& Management, vol. 204, article 112325, 2020. 
[35] A. N. Ozsezen, M. Canakci, A. Turkcan, and C. Sayin, "Performance and combustion characteristics of a DI diesel engine fueled with waste palm oil and canola oil methyl esters," Fuel, vol. 88, no. 4, pp. 629-636, 2009.

[36] E. G. Giakoumis, D. C. Rakopoulos, and C. D. Rakopoulos, "Combustion noise radiation during dynamic diesel engine operation including effects of various biofuel blends: a review," Renewable \& Sustainable Energy Reviews, vol. 54, pp. 10991113, 2016.

[37] S. Ma, Z. Zheng, H. Liu, Q. Zhang, and M. Yao, "Experimental investigation of the effects of diesel injection strategy on gasoline/diesel dual-fuel combustion," Applied Energy, vol. 109, pp. 202-212, 2013.

[38] A. A. Boretti, "Numerical evaluation of the performance of a compression ignition CNG engine for heavy duty trucks with an optimum speed power turbine," International Journal of Engineering and Technology Innovation, vol. 1, no. 1, pp. 1226, 2011.

[39] R. B. Semin and R. Ismail, "Investigation of diesel engine performance based on simulation," American Journal of Applied Sciences, vol. 5, no. 6, pp. 610-617, 2008.

[40] K. Nikzadfar and A. H. Shamekhi, "Investigating the relative contribution of operational parameters on performance and emissions of a common-rail diesel engine using neural network," Fuel, vol. 125, pp. 116-128, 2014.

[41] R. Mikalsen and A. P. Roskilly, "Coupled dynamic-multidimensional modelling of free-piston engine combustion," Applied Energy, vol. 86, no. 1, pp. 89-95, 2009.

[42] H. M. Ismail, H. K. Ng, S. Gan, T. Lucchini, and A. Onorati, "Development of a reduced biodiesel combustion kinetics mechanism for CFD modelling of a light-duty diesel engine," Fuel, vol. 106, pp. 388-400, 2013.

[43] L. Lešnik, J. Iljaž, A. Hribernik, and B. Kegl, "Numerical and experimental study of combustion, performance and emission characteristics of a heavy-duty DI diesel engine running on diesel, biodiesel and their blends," Energy Conversion and Management, vol. 81, pp. 534-546, 2014.

[44] A. Albrecht, V. Knop, G. Corde, L. Simonet, and M. Castagné, "Observer design for downsized gasoline engine control using 1D engine simulation," Oil and Gas Science and Technology, vol. 61, no. 1, pp. 165-179, 2006.

[45] K. Muralidharan and D. Vasudevan, "Performance, emission and combustion characteristics of a variable compression ratio engine using methyl esters of waste cooking oil and diesel blends," Applied Energy, vol. 88, no. 11, pp. 3959-3968, 2011.

[46] B. Zhang, E. Jiaqiang, J. K. Gong et al., "Multidisciplinary design optimization of the diesel particulate filter in the composite regeneration process," Applied Energy, vol. 181, pp. 14-28, 2016.

[47] B. Zhang, H. Y. Zuo, Z. H. Huang, J. Q. Tan, and Q. S. Zuo, "Endpoint forecast of different diesel- biodiesel soot filtration process in diesel particulate filters considering ash deposition," Fuel, vol. 272, p. 117678, 2020.

[48] G. Wu, D. Wu, Y. L. Li, and L. Meng, "Effect of acetone-nbutanol-ethanol (ABE) as an oxygenate on combustion, performance, and emission characteristics of a spark ignition engine," Journal of Chemistry, vol. 2020, 11 pages, 2020.

[49] J. Li, W. M. Yang, H. An, and D. Zhao, "Effects of fuel ratio and injection timing on gasoline/biodiesel fueled RCCI engine: a modeling study," Applied Energy, vol. 155, pp. 59-67, 2015.
[50] K. X. Wei, Y. Yang, H. Y. Zuo, and D. Zhong, “A review on ice detection technology and ice elimination technology for wind turbine," Wind Energy, vol. 23, no. 3, pp. 433-457, 2020.

[51] H. Y. Zuo, G. L. Liu, E. Jiaqiang et al., "Catastrophic analysis on the stability of a large dish solar thermal power generation system with wind-induced vibration," Solar Energy, vol. 183, pp. 40-49, 2019.

[52] H. Q. Chu, Y. C. Ya, F. Qiao, X. K. Nie, and E. Jiaqiang, "Effects of adding cyclohexane, n-hexane, ethanol, and 2,5-dimethylfuran to fuel on soot formation in laminar coflow n-heptane/iso-octane diffusion flame," Combustion and Flame, vol. 225, pp. 120-135, 2021.

[53] F. Zhang, G. Liao, E. Jiaqiang, J. Chen, and E. Leng, "Comparative study on the thermodynamic and economic performance of novel absorption power cycles driven by the waste heat from a supercritical $\mathrm{CO}_{2}$ cycle," Energy Conversion and Management, vol. 228, p. 113671, 2021.

[54] Q. G. Peng, W. M. Yang, E. Jiaqiang et al., "Effect analysis on properties enhancement of premixed $\mathrm{H}_{2} / \mathrm{C}_{3} \mathrm{H}_{8}$ /air combustion in porous medium micro combustor for the micro TPV applicationInvestigation on premixed $\mathrm{H} 2 / \mathrm{C} 3 \mathrm{H} 8$ /air combustion in porous medium combustor for the micro thermophotovoltaic application," Applied Energy, vol. 260, p. 114352, 2020.

[55] X. H. Zhao, E. Jiaqiang, G. L. Liao, F. Zhang, J. W. Chen, and Y. W. Deng, "Numerical simulation study on soot continuous regeneration combustion model of diesel particulate filter under exhaust gas heavy load," Fuel, vol. 287, p. 119795, 2021.

[56] E. Jiaqiang, M. Zhao, Q. Zuo et al., "Effects analysis on diesel soot continuous regeneration performance of a rotary microwave-assisted regeneration diesel particulate filter," Fuel, vol. 260, p. 116353, 2020.

[57] Q. S. Zuo, Y. Y. Tang, G. H. Zhu et al., "Investigations on the soot combustion performance enhancement of a catalytic gasoline particulate filter in equilibrium state for reducing the BSFC of gasoline direct injection engine," Fuel, vol. 284, p. 119032, 2021.

[58] Y. Xie, Q. S. Zuo, G. H. Zhu et al., "Investigations on the soot combustion performance enhancement of an improved catalytic gasoline particulate filter regeneration system under different electric heating powers," Fuel, vol. 283, p. 119301, 2021.

[59] E. Jiaqiang, P. Zheng, D. Han, X. Zhao, and Y. Deng, "Effects analysis on soot combustion performance enhancement in a rotary diesel particulate filter unit during continuous microwave heating," Fuel, vol. 276, p. 118043, 2020.

[60] H. Chu, L. Xiang, X. Nie, Y. Ya, M. Gu, and E. Jiaqiang, "Laminar burning velocity and pollutant emissions of the gasoline components and its surrogate fuels: A review," Fuel, vol. 269, article 117451, 2020.

[61] H. Chu, L. Xiang, X. Nie, Y. Ya, M. Gu, and E. Jiaqiang, "Effects of ethanol and 2,5-dimethylfuran addition on the morphology and nanostructure evolution of soot in gasoline primary reference fuel-air coflow diffusion flames," Fuel, vol. 269, article 118711, 2020. 